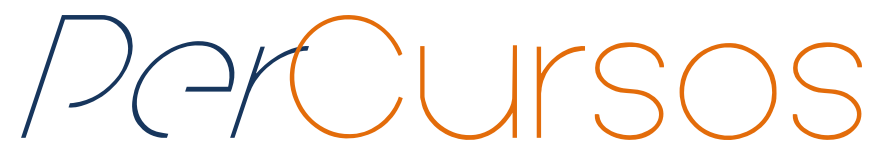

\title{
Linguagem fotográfica e ensino de Geografia: experiências desenvolvidas no PIBID/Geografia/UFGD ${ }^{1}$
}

\begin{abstract}
Resumo
Considerando a importância e papel fundamental que o Programa Institucional de Bolsa de Iniciação à Docência (PIBID) tem desempenhado na formação de professores nos últimos anos, neste artigo, apresentamos e refletimos sobre algumas experiências desenvolvidas no âmbito desse programa. Nessas experiências, desenvolvidas com alunos do Ensino Fundamental e Médio em escolas da rede estadual de Dourados (MS), procurou-se trabalhar o potencial das linguagens imagéticas, sobretudo a linguagem fotográfica, no ensino de Geografia. O principal objetivo foi permitir o estabelecimento de sentidos geográficos menores a partir da interpretação de registros imagéticos dos alunos da educação básica em relação a temas e situações por eles vivenciados ou observados, além de exercitar habilidades de ensino e aprendizagem geográficas por meio de análises sobre a linguagem fotográfica. Pode-se dizer que o trabalho despertou um olhar mais apurado dos alunos sobre suas vivências e experiências espaciais cotidianas a partir das imagens registradas por eles próprios. As fotografias produzidas pelos alunos provocaram o movimento do pensamento, na medida em que impulsionaram aqueles que as observaram a identificarem elementos, estabelecerem relações, comparações e produzirem indagações sobre o observado. Num momento em que vivenciamos uma série de indefinições e ameaças quanto ao futuro e manutenção do PIBID, defendemos que esse programa contribui significativamente para a formação de professores, assim como para a educação básica. Acreditamos que as experiências e reflexões aqui realizadas trazem elementos que demonstram algumas dessas contribuições.
\end{abstract}

Palavras-chave: Linguagem Fotográfica; Ensino de Geografia; PIBID.

\author{
Flaviana Gasparotti Nunes \\ Doutora em Geografia pela \\ Universidade Estadual Paulista \\ "Júlio de Mesquita Filho" - \\ UNESP. Professora da \\ Universidade Federal da Grande \\ Dourados - UFGD. \\ Brasil \\ flaviananunes@ufgd.edu.br
}

\section{Para citar este artigo: \\ NUNES, Flaviana Gasparotti. Linguagem fotográfica e ensino de Geografia: experiências desenvolvidas no PIBID/Geografia/UFGD. Revista PerCursos, Florianópolis, v. 17, n.35, p. 28 - 48, set./dez. 2016.}

\section{DOI: $\mathbf{1 0 . 5 9 6 5 / 1 9 8 4 7 2 4 6 1 7 3 5 2 0 1 6 0 2 8}$}

http://dx.doi.org/10.5965/1984724617352016028

\footnotetext{
${ }^{1}$ Projeto Programa Institucional de Bolsa de Iniciação à Docência - PIBID, com apoio da Coordenação de Aperfeiçoamento de Pessoal de Nível Superior - CAPES/MEC.
} 


\title{
Photographic language and Geography education: experiences developed by the PIBID /Geography/UFGD
}

\begin{abstract}
Considering the importance and key role that the Institutional Program for scholarships for beginner teachers (PIBID) has played in teacher education in recent years, in this paper, we present and reflect on some experiments carried out under this program. In these experiments, developed with students from elementary and high schools in the state system schools in Dourados (MS), he tried to work the potential of imagistic language, especially the photographic language, in geography teaching. The main objective was to allow the establishment of smaller geographic directions from the interpretation of pictorial records of basic education students on issues and situations they experience or observe besides exercising geographical teaching and learning skills through analysis of the photographic language. It can be said that the work prompted a closer look at the students about their experiences and everyday spatial experiences from the images recorded by themselves. The photographs produced by students caused the movement of thought, to the extent that those who drove observed to identify elements establishing relationships, comparisons and on observed produce inquiries. At a time when we experience a number of uncertainties and threats for the future and maintaining PIBID, we argue that this program contributes significantly to the training of teachers as well as for basic education. We believe that the experiences and reflections presented here brings elements that demonstrate some of these contributions.
\end{abstract}

Keywords: Photographic Language; Geography Education; PIBID. 


\section{O PIBID/Geografia na UFGD: uma aposta na potência das linguagens} imagéticas

Dentre as mudanças ocorridas nos últimos anos na política de formação de professores, destaca-se, em 2007, a reformulação da lei que instituiu a Coordenação de Aperfeiçoamento do Pessoal de Nível Superior (CAPES). A partir dessa reformulação, a CAPES recebeu a atribuição de induzir e fomentar a formação inicial e continuada de profissionais da educação básica e estimular a valorização do magistério em todos os níveis e modalidades de ensino. A "Nova CAPES", como foi chamada, é um setor da Coordenação de Aperfeiçoamento de Pessoal de Nível Superior que se tornou responsável por ações referentes à formação dos professores, tanto inicial quanto continuada, assim como da educação básica².

Neste contexto, foi proposto o PIBID (Programa Institucional de Bolsa de Iniciação à Docência). A criação do PIBID teve a intenção de fomentar a iniciação à docência com a finalidade de melhor qualificá-la, mediante projeto específico de trabalho e concessão de bolsas, abrangendo as diferentes áreas do conhecimento que fazem parte do currículo da educação básica. Proposto em 2007, teve sua regulamentação mais detalhada pelo Decreto n. 7219/2010.

Na Universidade Federal da Grande Dourados (UFGD), o PIBID foi implantado em 2009 envolvendo, inicialmente, os seguintes cursos de licenciatura: Matemática, Ciências Biológicas, Geografia, História, Letras e Pedagogia. Em 2011, o PIBID/UFGD ampliou-se, passando a envolver as licenciaturas de Ciências Sociais, Psicologia, Química, Artes Cênicas e Educação Física. Nesse mesmo ano, houve a ampliação do número de bolsistas nos subprojetos implantados em 2009. Em 2014, foram incluídas três licenciaturas da Educação a Distância (UAB): Letras-Libras, Informática e Pedagogia. Atualmente, o PIBID/UFGD possui 418 bolsistas em 13 subprojetos.

Desde a implantação do PIBID na UFGD, coordenamos o subprojeto de Geografia que, inicialmente, contava com seis bolsistas de iniciação à docência, uma professora

\footnotetext{
${ }^{2}$ Decreto n. 6.755/2009 - que dispôs sobre a atuação da CAPES no fomento a programas de formação inicial e continuada dos professores.
} 
supervisora e uma escola parceira. O subprojeto desenvolvido naquele momento intitulado "A busca de aprendizagens significativas e os desafios do professor de Geografia na atualidade" tinha como foco o Ensino Médio e a alfabetização geográfica como referência, mas envolvia também um número grande de questões como: transposição didática, ENEM, linguagens, tecnologias da informação e comunicação (TICs), habilidades, entre outras. Num momento ainda bastante embrionário em relação às ações que o PIBID deveria realizar, a proposta desse primeiro subprojeto era ampla, o que trouxe algumas dificuldades em seu desenvolvimento.

Dentre os caminhos trilhados nesse período, sobressaiu-se o trabalho voltado ao Exame Nacional do Ensino Médio (ENEM) com ênfase na reflexão sobre as diferentes linguagens presentes nas questões desse exame. A partir de um levantamento realizado junto aos alunos do Ensino Médio da Escola Estadual Menodora Fialho de Figueiredo, onde as atividades do PIBID eram realizadas, constatou-se que uma das maiores dificuldades em relação à Geografia, referia-se à leitura e análise de mapas, gráficos, tabelas, entre outras linguagens não verbais. Além disso, os alunos do Ensino Médio também apontaram dificuldades para compreender algumas questões presentes no ENEM, principalmente aquelas que apresentavam tais linguagens em seus enunciados. Diante disso, passamos a desenvolver junto aos alunos dessa escola, um conjunto de atividades no contraturno, voltadas ao trabalho com as questões do ENEM, procurando explorar/trabalhar justamente as linguagens não verbais presentes em questões ligadas à Geografia. ${ }^{3}$ Destacamos, entre os produtos resultantes desse trabalho, o artigo de Sayão e Nunes (2011).

Já em 2011, passamos a desenvolver o subprojeto “O papel das linguagens no processo de alfabetização geográfica: referências para a formação do professor de Geografia" que objetivou contribuir para a formação inicial de professores de Geografia desenvolvendo reflexões teóricas e ações voltadas à análise e utilização de diferentes

\footnotetext{
${ }^{3}$ Falamos em questões ligadas à Geografia ou que apresentavam temas, questões, conceitos ou raciocínios geográficos, pois até 2008 a prova do Exame Nacional do Ensino Médio (ENEM) era composta por 63 itens interdisciplinares. Desta forma, não havia uma separação das questões em disciplinas específicas. Em 2009, a proposta do ENEM foi reformulada e o Exame passou a ser composto por perguntas objetivas em quatro áreas do conhecimento: linguagens, códigos e suas tecnologias (incluindo redação); ciências humanas e suas tecnologias; ciências da natureza e suas tecnologias e matemáticas e suas tecnologias.
} 
linguagens como base para o desenvolvimento do processo de alfabetização geográfica no ensino básico. Nesse momento, tivemos a ampliação do número de bolsistas, que passou a ser de 12 bolsistas de iniciação à docência, dois professores supervisores e duas escolas parceiras ${ }^{4}$.

Desde então, temos desenvolvido um conjunto de ações ${ }^{5}$ nas quais procuramos destacar/explorar a potência que as linguagens, sobretudo as imagéticas (mapas, fotografias, vídeos, desenhos, entre outras), possuem para a elaboração de referenciais e raciocínios espaciais.

Quando nos referimos ao papel ou potência das linguagens na elaboração de referenciais e raciocínios espaciais, estamos entendendo-as para além de simples recursos ou ferramentas didáticas. Entendemo-las em seu sentido criador, produtor de sentidos, criadoras de mundos e de pensamentos acerca do espaço geográfico, conforme nos apontam Oliveira Junior e Girardi (2011, p. 04):

Podemos avançar na problematização do tema das diferentes linguagens no ensino da geografia, tratando as linguagens não somente como componentes do ato comunicativo, mas também, e sobretudo, como viabilizadoras de novas produções de mundo. E seguir nesta problematização implica, necessariamente, em questionar o próprio conteúdo do processo comunicativo.

Abordar as diferentes linguagens é entendê-las não estritamente como elemento de um processo de comunicação, mas como fundamento de um processo de criação, de produção de pensamento sobre o espaço.

Neste sentido, para os referidos autores, é necessário tomar as linguagens como criadoras, ou seja, potencializadoras de pensamentos sobre o espaço, na medida em que

\footnotetext{
${ }^{4}$ Em 2012 foi implantado outro subprojeto no âmbito do PIBID/Geografia na UFGD intitulado "Ensino de Geografia e o uso da linguagem pictórica" que possibilitou mais uma ampliação do número de bolsistas de iniciação à docência, de supervisores e escolas parceiras e desenvolveu-se em diálogo com o subprojeto sob nossa coordenação.

${ }^{5}$ As ações que configuram o trabalho desenvolvido pelo PIBID/Geografia/UFGD nas escolas de educação básica parceiras envolvem: aulas e oficinas no contraturno; monitoria e atividades nas aulas regulares das professoras supervisoras; elaboração de propostas e materiais para feiras e exposições, entre outras.
} 
“(...) o mundo produz linguagens tanto quanto linguagens produzem o mundo" (OLIVEIRA JUNIOR. \& GIRARDI, 2011, p. 4).

Deste modo, as linguagens não são apenas componentes do ato comunicativo, fazem parte de novas produções do mundo. Abordar as diferentes linguagens é analisar a produção de pensamento sobre o espaço e não apenas compreender como um processo de comunicação:

(...) Em outras palavras, as próprias linguagens são tomadas como obras humanas nas quais se pode ou não, se consegue ou não dizer algo. $A$ escolha de uma linguagem para dizer alguma coisa, para criar alguma coisa é já uma escolha que definirá o conteúdo que será dito. Forma e conteúdo não se desgrudam, não se separam, mas antes se coadunam na gestação de pensamentos e obras. (OLIVEIRA JUNIOR. \& GIRARDI, 2011, p. 4)

Também partimos do entendimento de que a Geografia possui uma linguagem própria. Neste sentido, a alfabetização geográfica compreende o desenvolvimento e apropriação dessa linguagem para um determinado tipo de leitura - a da espacialidade dos fenômenos. Trata-se de um exercício em busca de ferramentas cognitivas que permitam olhar e entender o mundo ultrapassando os limites da simples sensação. (SANTOS, 2007).

Assim, a apropriação da linguagem geográfica se dá a partir da construção de conceitos e habilidades que possibilitam ao aluno ler o espaço, mediado pela compreensão dos elementos que o compõem, bem como pela lógica de construção deste, que será apreendida por meio da utilização e aplicação dos conceitos à realidade.

Desta forma, além da construção dos conceitos geográficos, que podem ser trabalhados desde o início do processo de alfabetização, é necessário desenvolver habilidades que capacitem o aluno a se apropriar de tais conceitos. As linguagens, portanto, cumprem um papel fundamental, na medida em que potencializam que tais habilidades sejam desenvolvidas. 
Em vista das compreensões até aqui expostas, nosso intuito neste texto é apresentar e refletir sobre duas experiências realizadas no âmbito do PIBID/Geografia/UFGD voltadas ao trabalho com a linguagem fotográfica.

\section{Contextualizando as experiências com a linguagem fotográfica}

Considerando o entendimento das linguagens para além de meros recursos didáticos que ilustram ou representam o conteúdo, tomamos as imagens fotográficas enquanto linguagem que permite a criação de pensamentos sobre o espaço. Nas palavras de Oliveira Junior (2009, p. 10):

As imagens fotográficas assumem, neste contexto, fundamental importância, porque: Não só por nos darem a visualidade dos lugares, estas imagens estão a grafar em nós pensamentos sobre o espaço geográfico. Impregnados no visual, nos chegam também sentidos para estes lugares, maneiras de significá-los uns em relação aos outros, propondo-nos raciocínios e imaginações acerca de cada um deles e das relações que existem entre eles. (OLIVEIRA JUNIOR, 2009, p. 10)

Verticalizando nesta direção, destacamos a ideia de Humberto (2000, p. 47) apud Oliveira Junior (2009, p. 11):

A fotografia é a visão de uma realidade reinterpretada, escolhida muitas vezes a partir de sonhos pouco duráveis. Alucinação retida e vivida só na imaginação. Só lembranças. Uma espécie de viagem impune, na busca de razões. Ineficiente tentativa de explicar, mas que faz pensar.

Boris Kossoy (2002, p. 27):, um dos principais pensadores sobre a fotografia, problematiza a ideia da fotografia entendida como "prova de realidade". Para o autor

O assunto, tal como se acha representado na imagem fotográfica, resulta de uma sucessão de escolhas; é fruto de uma somatória de seleções de diferentes naturezas - idealizadas e conduzidas pelo fotógrafo-seleções 
essas que ocorrem mais ou menos concomitantes e que integram entre si, determinando o caráter da representação.

As fotografias aprisionam recortes feitos no espaço pelo olhar do fotógrafo objetivando alcançar algo. Segundo Kossoy (2002, p. 38): “(...) a realidade da fotografia reside nas múltiplas interpretações, nas diferentes leituras que cada receptor dela faz num dado momento (...)”. Tantas leituras tornam-se possíveis porque as fotografias provocam em nós sensações também diferentes.

A partir dessas reflexões, bem como motivados pela afirmação de Oliveira Junior e Soares (2012, p. 132) de que é necessário “(...) que professores e alunos passem a lidar com as fotografias em situações didáticas para além do sentido documental", é que nos anos de 2012 e 2015, desenvolvemos duas experiências no âmbito das atividades do PIBID/Geografia/UFGD.

A primeira experiência foi realizada no ano de 2012 quando foram desenvolvidas oficinas que culminaram em duas exposições fotográficas: "Imagens do urbano: geografias a partir do olhar do aluno" e "Imagens do bairro e da escola: geografias a partir do olhar do aluno". As oficinas foram coordenadas pelos bolsistas de iniciação à docência e envolveram alunos do Ensino Fundamental e Médio das Escolas Estaduais Celso Muller do Amaral e Menodora Fialho de Figueiredo, município de Dourados (MS), onde são realizadas as atividades do PIBID. A realização das oficinas teve como principal objetivo permitir o estabelecimento de sentidos geográficos menores a partir da interpretação dos registros imagéticos dos alunos do ensino básico em relação a temas e situações por eles vivenciadas ou observadas. A ideia de sentidos geográficos menores deriva das reflexões de Oliveira Junior (2014, p. 1) em torno do que o autor chama de geografias menores. Nos dizeres do autor:

A expressão geografias menores é tributária de nosso contágio com alguns conceitos da filosofia da diferença, sobretudo os conceitos de minoridade, resistência e fabulação, provenientes de diversas obras de Gilles Deleuze e Félix Guattari. Ela foi cunhada com a intenção de explicitar um combate pela expansão das margens da Geografia no que se refere às suas relações com as linguagens que se expressam em 
imagens, tais como o cinema, a fotografia e o vídeo (Oliveira Junior, 2009; 2010; 2013) (...) Geografias menores são forças minoritárias que se agitam no interior da Geografia maior. Não existem como formas acabadas, mas como potência de devir naquilo que já está estabelecido. Seriam, portanto, todas aquelas forças (conceituais, formais, temáticas, metodológicas etc.) que operam rupturas, fraturas e esburacamentos, oscilações, dúvidas e incorporações novas naquilo que antes já era Geografia. São antes aquilo que promove outras conexões e possibilidades, não necessariamente rompimentos ou negações; ampliam as margens em que o pensamento geográfico se dá, abrindo nele novos possíveis. (OLIVEIRA JUNIOR, 2014, p. 1)

Além disso, também objetivou-se exercitar as habilidades de ensino e aprendizagem geográficas por meio de análises sobre a linguagem imagética, notadamente a fotográfica; estimular o contato e o uso de novas tecnologias, como câmeras digitais e telefones celulares; permitir trocas de experiências entre professores e alunos de diferentes escolas e bairros, incentivando conhecimento de suas singularidades e potencializando suas identidades a partir da detecção de questões comuns em seus ambientes. A partir destes objetivos foram pensadas temáticas que resultassem em imagens fotográficas que expressassem as diferentes geografias dos alunos.

A exposição na Escola Estadual Celso Muller ocorreu a partir do trabalho realizado com os alunos dos sétimos e oitavos anos do Ensino Fundamental. As turmas foram divididas em grupos de até cinco alunos e cada grupo foi orientado a produzir, pelo menos, seis fotos, sobre os seguintes temas: "Como é o meu bairro"; "Os problemas ambientais no meu bairro"; "Os detalhes do meu bairro"; "Como é minha escola" e "O bom e o mau da minha escola" de forma que as fotos retratassem, pelo olhar dos alunos, o seu espaço de vivência e interação social. A partir do conjunto de fotos elaboradas pelos alunos, foram selecionadas pelos bolsistas do PIBID $^{6}, 15$ fotos das duas turmas para serem impressas em banners que compuseram a exposição fotográfica realizada em novembro de 2012 (Figura 1).

\footnotetext{
${ }^{6}$ O principal critério utilizado para esta seleção foi que as fotos fugissem dos clichês e convenções habituais de cada tema, seja pelas características do fato ou elemento fotografado, seja pela forma de fotografar.
} 


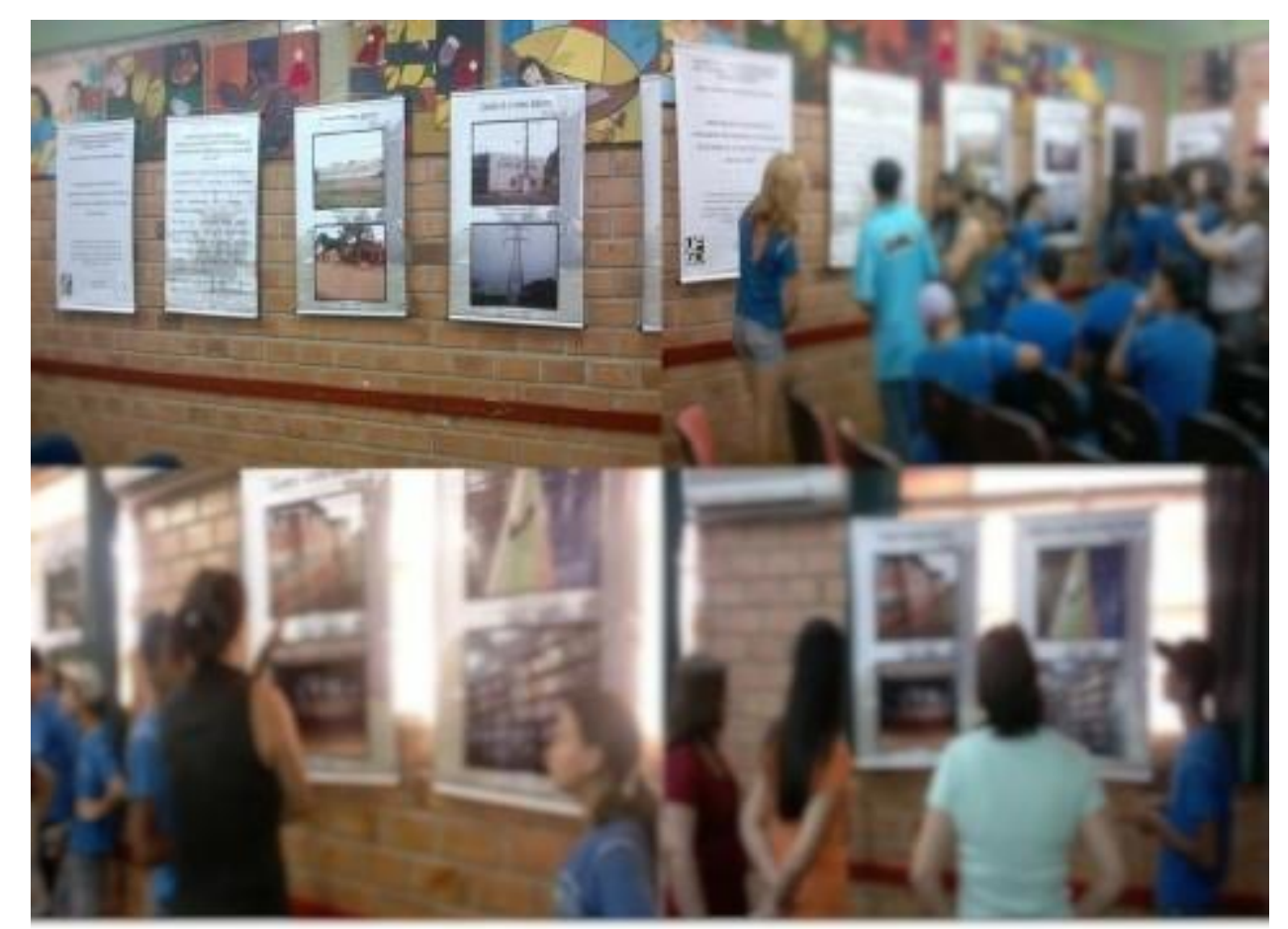

Figura 1 - Exposição fotográfica "Imagens do bairro e da escola: geografias a partir do olhar do aluno". Fonte: Acervo pessoal da autora.

Já na Escola Estadual Menodora Fialho de Figueiredo, o trabalho foi desenvolvido com as turmas de $1^{\circ}, 2^{\circ}$ e $3^{\circ}$ anos do Ensino Médio, participantes das atividades do PIBID/Geografia/UFGD. Os alunos foram orientados a fotografarem a cidade de Dourados sob diferentes olhares, tais como: a cidade de forma geral, o bairro em que moram, a casa em que vivem, mostrando através das imagens entendimentos quanto ao feio, ao belo e aos problemas ambientais desses lugares. Da mesma forma, as fotografias que compuseram a exposição foram selecionadas pelos bolsistas do PIBID/Geografia atendendo aos critérios já mencionados. Cada grupo de alunos pode expor, através das imagens fotográficas, visões de mundo, maneiras como enxergam uns aos outros e o lugar onde vivem, em muitas delas, demonstrando a dimensão reveladora do não visto. (Figura 2) 


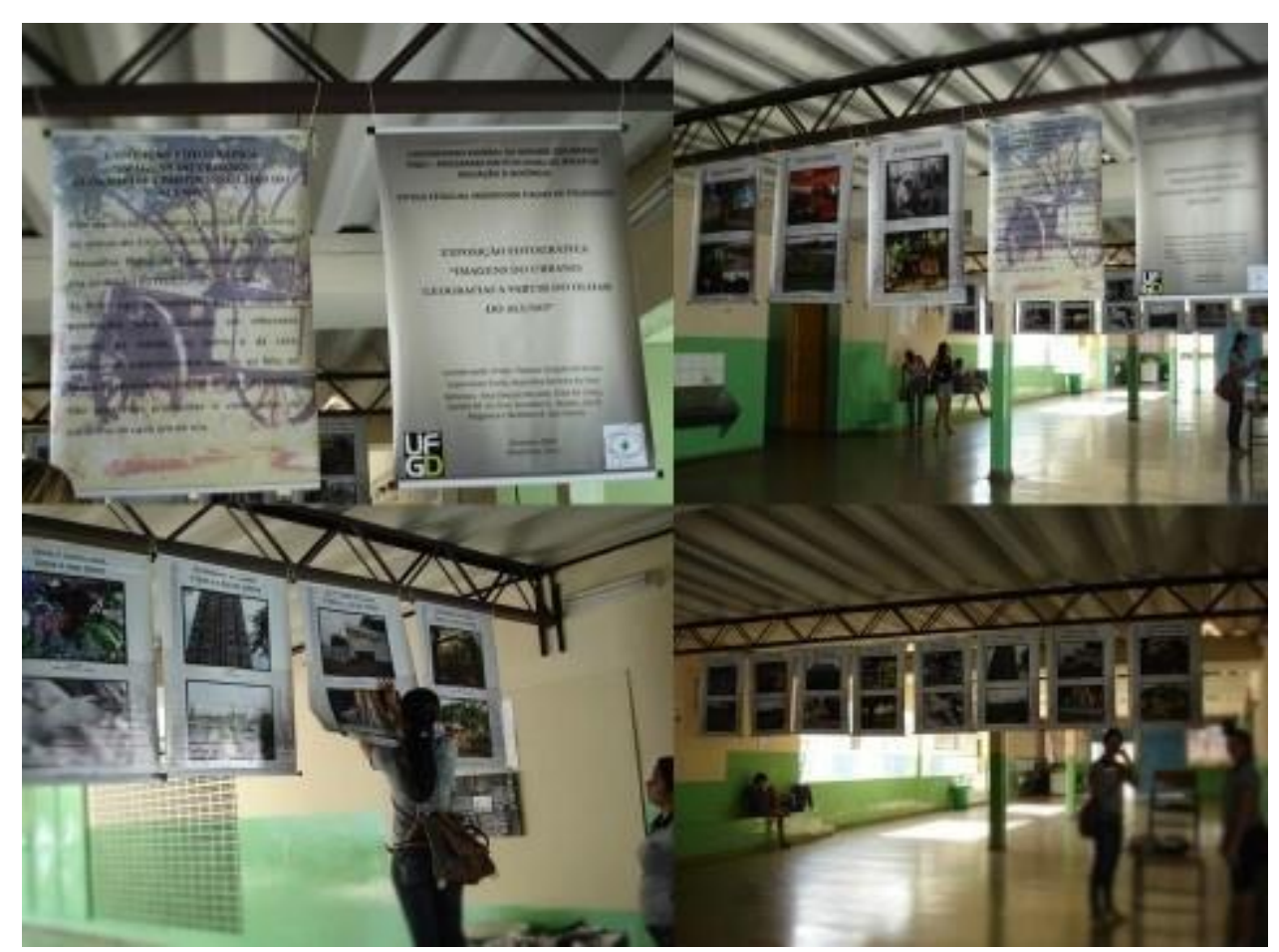

Figura 2 - Exposição fotográfica Imagens do urbano: geografias a partir do olhar do aluno. Fonte: Acervo pessoal da autora.

A segunda experiência ocorreu em 2015 e culminou com a exposição fotográfica "Olhares sobre os afrodescendente em Dourados" realizada na Escola Estadual Menodora Fialho de Figueiredo durante a Semana da Consciência Negra. O trabalho envolveu alunos do $2^{\circ}$ e $3^{\circ}$ anos do Ensino Médio que foram organizados em grupos, sendo cada grupo responsável por fotografar a partir dos seguintes temas: Os afrodescendentes em Dourados (Onde estão? Como são? O que fazem?); O preconceito etnicorracial e suas expressões em Dourados; A presença e influências dos afrodescendente em Dourados. (Figura 3)

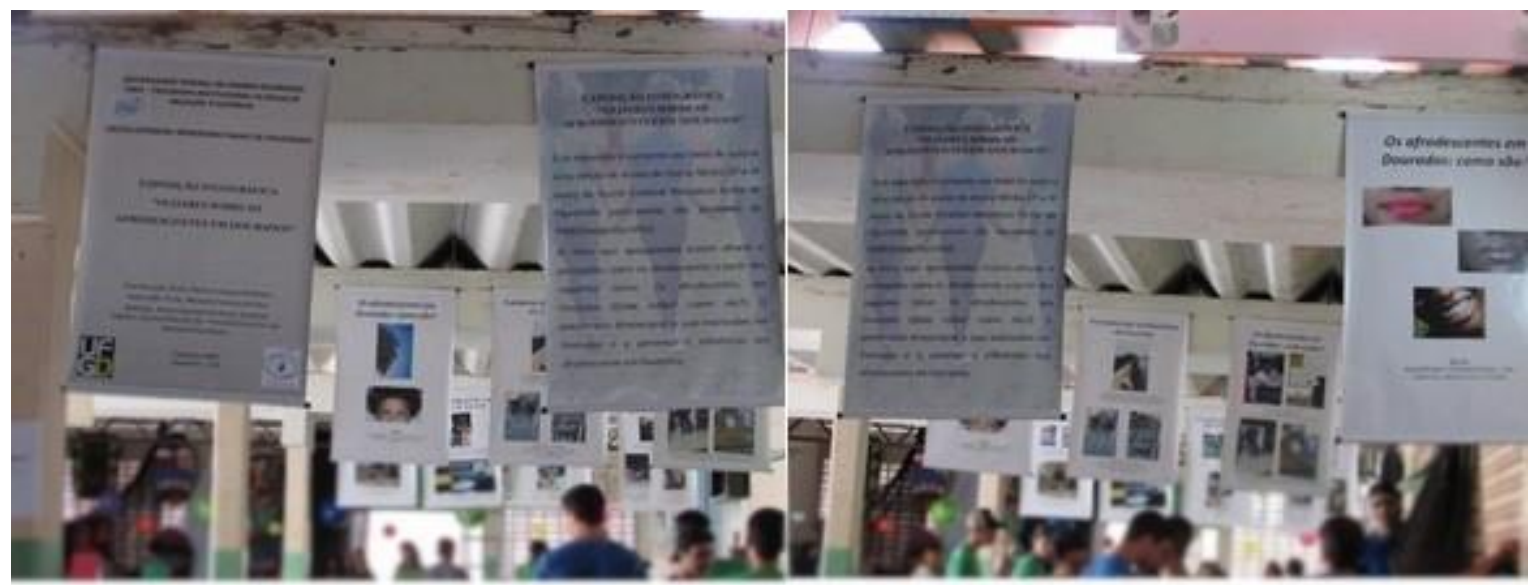


Figura 3 - Exposição fotográfica "Olhares sobre os afrodescendentes em Dourados" . Fonte: Acervo pessoal da autora.

No intuito de demonstrarmos como a experiência permitiu e enfatizou as potencialidades da linguagem fotográfica no ensino de Geografia, no próximo subitem destacaremos e discutiremos algumas das fotografias que compuseram as exposições.

\section{O que as fotos dos alunos (nos) dizem?}

A exposição fotográfica "Imagens do urbano: geografias a partir do olhar do aluno", realizada em 2012 na Escola Estadual Menodora Fialho de Figueiredo, foi composta por 22 fotografias. Sobre o tema "O que é Dourados?", destacamos as fotos das Figuras 4 e 5:

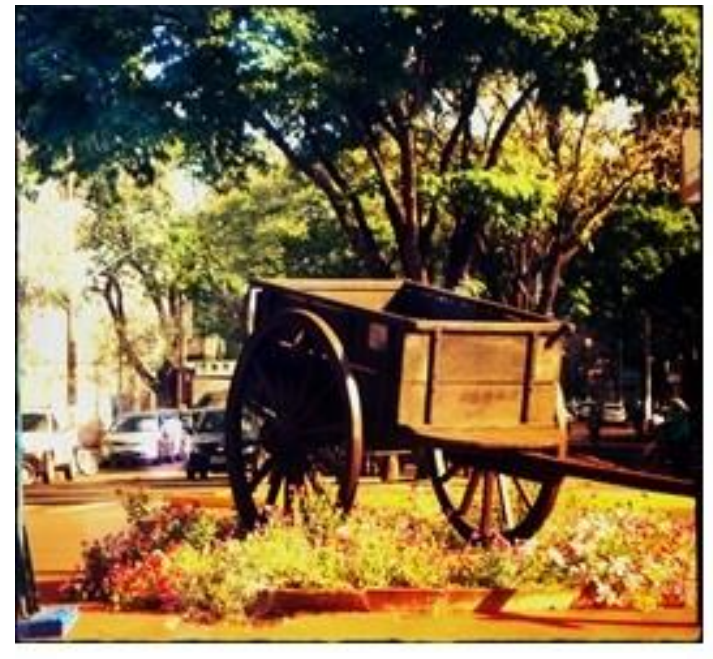

Figura 4- Monumento. Autoria: Sara Rolin Lopes.

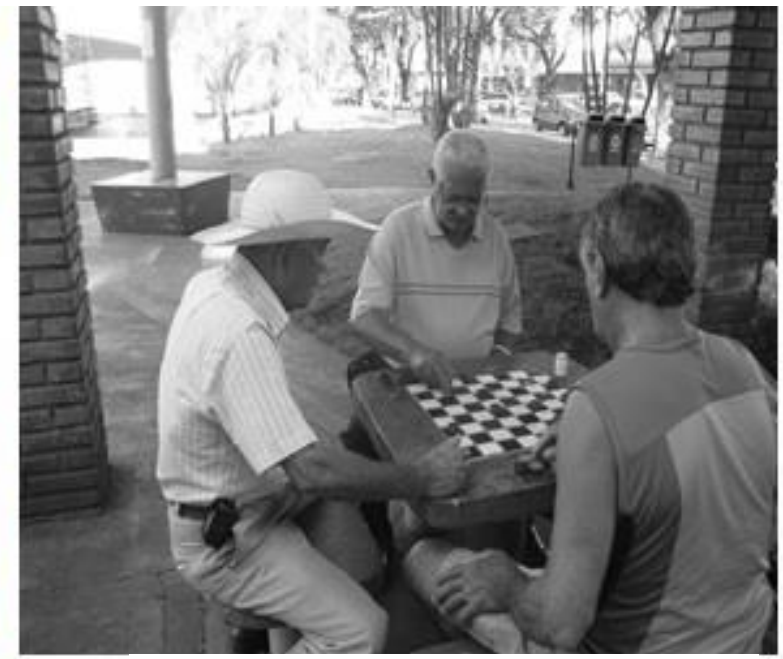

Figura 5 - A vida depois dos 60 Autoria: Sara Rolin Lopes

O monumento: uma carroça. A vida depois dos 60: um jogo de dominó na Praça Antônio João. Imagens que para Sara, aluna no Ensino Médio, dizem o que é Dourados. Mas não só para Sara essas fotografias dizem de Dourados. A carroça remete à história, ao período de fundação do município, mas também remete ao presente. Diversas carroças circulam nas ruas de Dourados até hoje. Quem utiliza as carroças atualmente em Dourados? Principalmente os indígenas! Portanto, passado e presente de Dourados podem ser pensados a partir da imagem da carroça. Para alguns, monumento em homenagem aos "heróis e pioneiros" dos tempos passados; para outros, símbolo da 
opressão a que foram e são submetidos até os dias de hoje milhares de indígenas que já habitavam essas terras.

Dourados também é a praça central e o que nela acontece. Na praça Antônio João, entre outras atividades, é possível encontrar senhores de mais idade, geralmente aposentados, em momentos de descontração, jogando dominó, por exemplo. A foto da Figura 5, de maneira geral, seja pela cena, seja pela opção da aluna em utilizar as cores preto e branco, traz a sensação de que Dourados é um lugar calmo, tranquilo. Será mesmo?

“Como é minha casa? Como é meu bairro?”. Este foi outro tema proposto aos alunos do Ensino Médio no contexto em que o urbano era o foco. No entanto, surgiram imagens como a da foto da Figura 6:

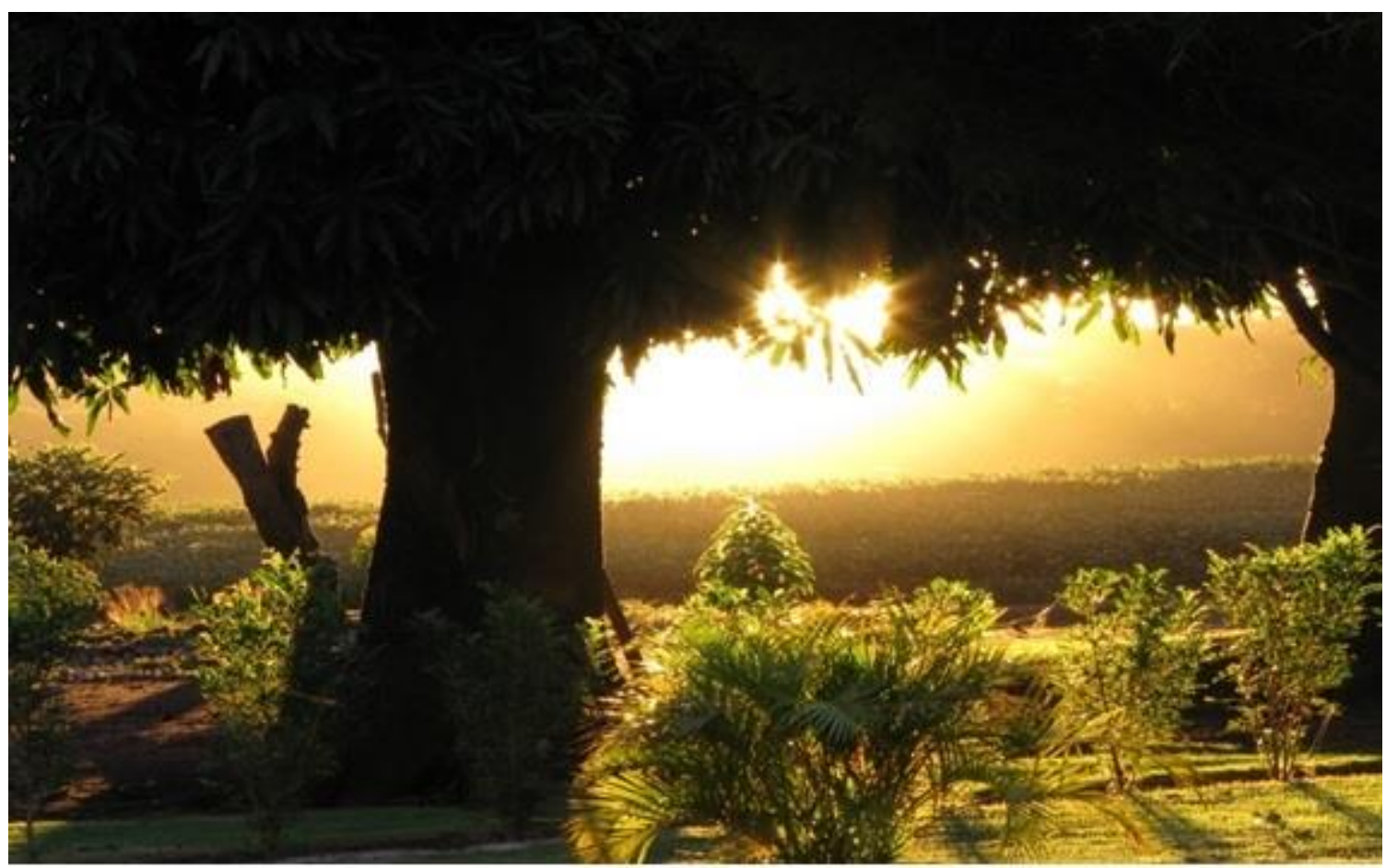

Figura 6 - O entardecer no sítio. Autoria: Carolina A. Araújo.

O bairro e a casa de Carolina fogem à ideia convencional de bairro e casa no contexto do urbano, pois, trata-se de um sítio! A bela imagem do entardecer no sítio traz para a aluna significados do seu lugar de vivência, é parte de sua geografia. Mas, ao mesmo tempo, a imagem permite questionar: Que cidade é essa em que um bairro tem 
características do campo? Que bairro é esse que não apresenta características urbanas, mas ao mesmo tempo é parte da cidade? Que cidade é essa em que urbano e rural se misturam? Que sentidos possui o urbano em Dourados? Como se manifestam esses sentidos?

A segunda exposição realizada em 2012 ocorreu na Escola Estadual Celso Muller do Amaral e foi intitulada "Imagens do bairro e da escola: geografias a partir do olhar do aluno", sendo composta por 32 fotos. A foto da Figura 7 referiu-se ao tema "Os detalhes do meu bairro":

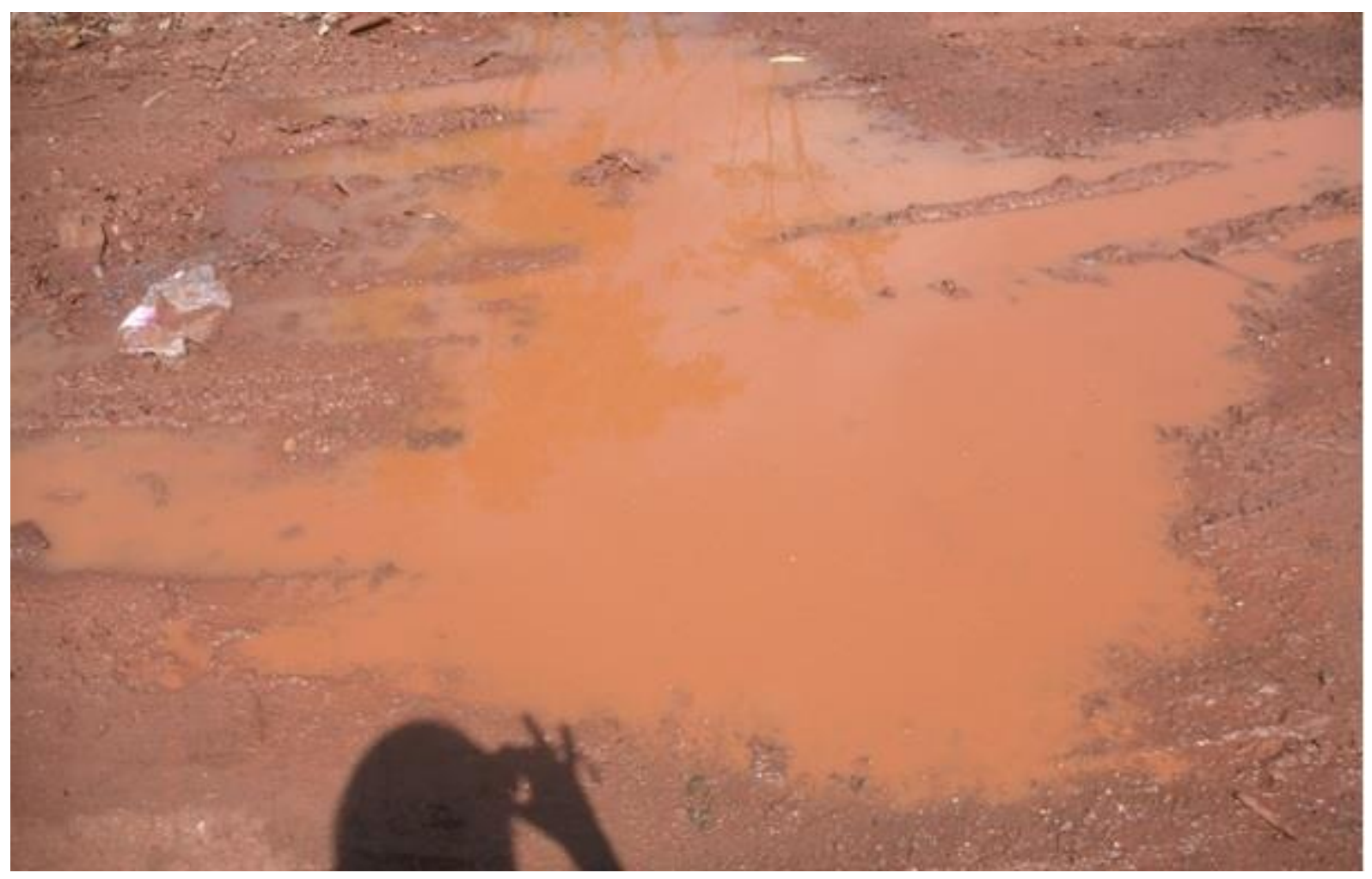

Figura 7 - Estrada lamacenta. Autoras: Camila e Andressa.

Camila e Andressa, autoras da foto, a intitularam “Estrada lamacenta”. Para elas, a imagem traz um detalhe significativo do bairro onde vivem: a ausência de pavimentação asfáltica. As marcas da passagem de veículos sobre a lama foram destacadas na foto. Pode-se questionar: o intuito das alunas foi evidenciar a dificuldade de locomoção no bairro devido à falta de pavimentação asfáltica? Por que falta pavimentação asfáltica nesse bairro? Que consequências isso traz para os moradores em seu cotidiano? Que 
alternativas buscam para ir ao trabalho, à escola, para se locomoverem em dias de “estradada lamacenta”? Quantos bairros de Dourados apresentam a mesma situação?

Outro tema abordado nessa exposição foi "O bom e o mau na minha escola". As fotos das Figuras 8 e 9 foram elaboradas a partir desse tema.

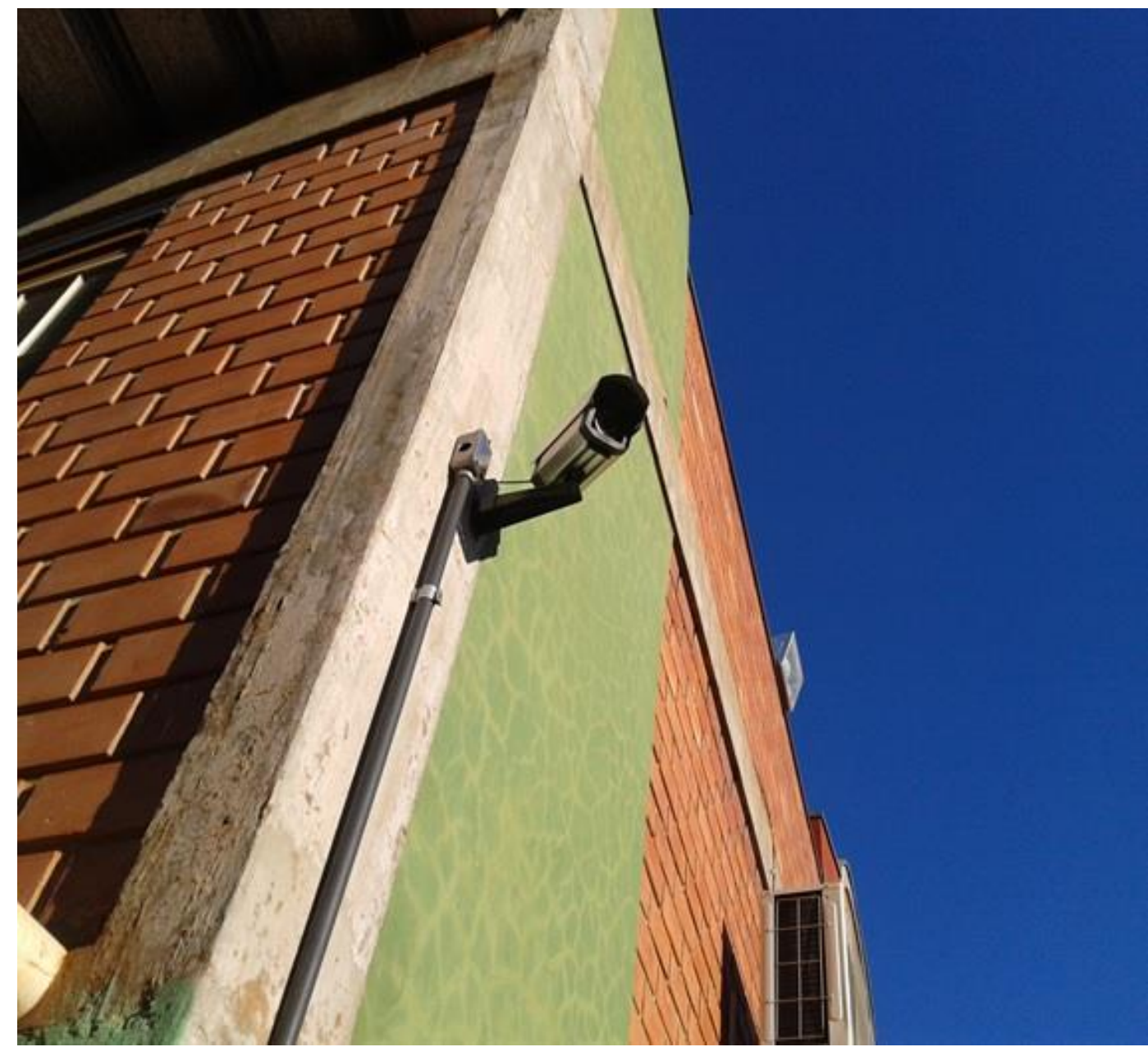

Figura 8 - Câmeras na escola. Autora: Thatiele da Silva Cruz.

A foto da Figura 8 nos pareceu bastante provocativa, pois traz um sentido dúbio: a presença de câmeras na escola é boa ou ruim? Garante segurança ou significa constante vigilância e controle dos alunos, professores e funcionários? Por que foram instaladas? Qual a geografia de uma sociedade e de um mundo no qual a vigilância se impõe como necessidade justificada pela garantia de segurança? A escola não é um lugar seguro? Para que servem as câmeras na escola? 


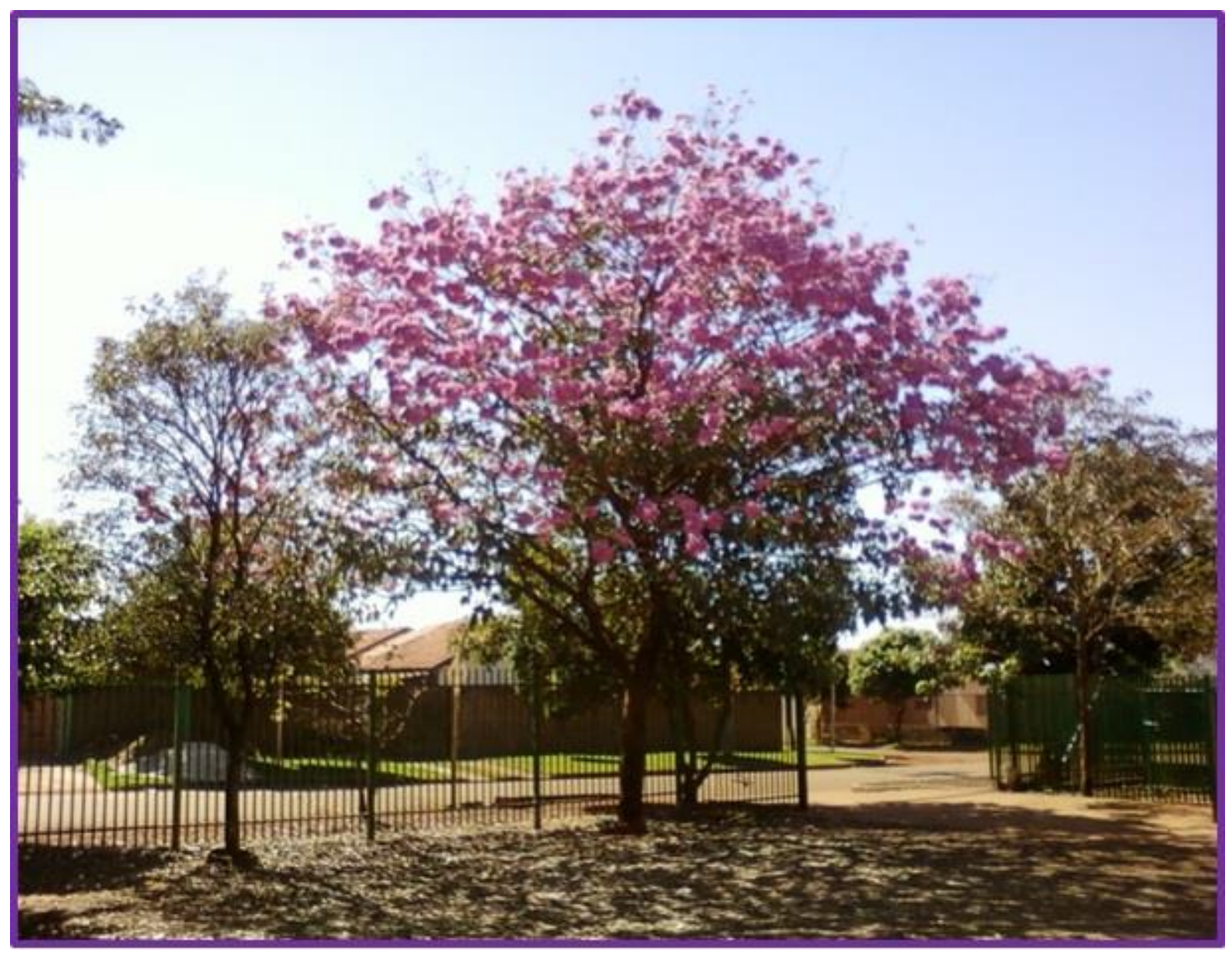

Figura 9 - Ipê rosa na escola. Autoras: Elizabetty e Ágata.

Elizabetty e Ágata emolduraram a foto com a mesma cor das flores do ipê que existe em frente à escola. Em alguns meses do ano, o ipê fica florido. A escola, por vezes, é chata. Mas a beleza do ipê rosa florido, na entrada da escola, torna aquele lugar menos duro e disciplinador. É possível encontrar o bom na escola?

Passando à segunda experiência, ocorrida em 2015 com a exposição fotográfica “Olhares sobre os afrodescendentes em Dourados", realizada na Escola Estadual Menodora Fialho de Figueiredo durante a Semana da Consciência Negra, destacamos as fotos das Figuras 10, 11 e 12. 


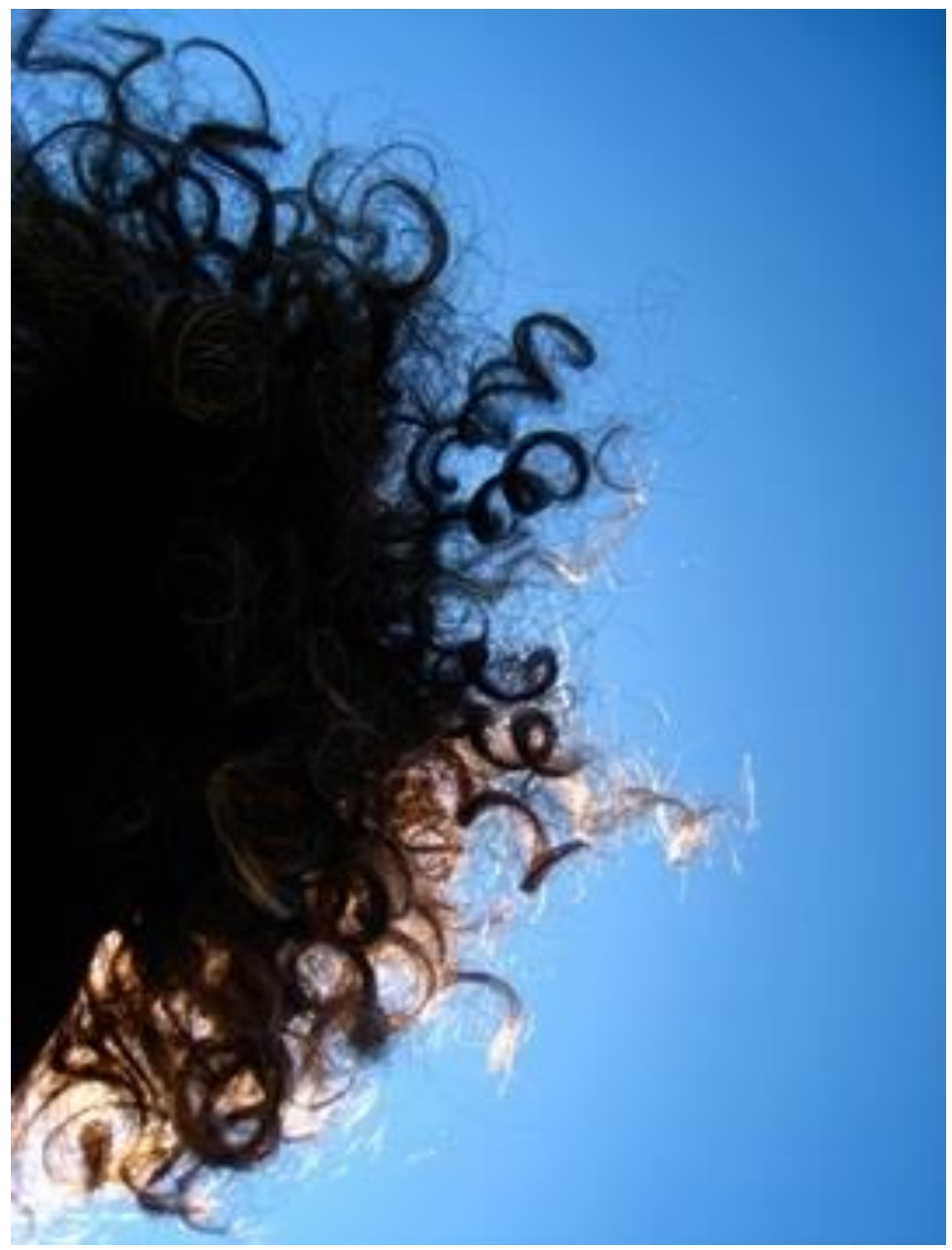

Figura 10 - Cabelos. Autoria: Fernanda Ikizumi, Vitor Gutierres, Jéssica Lima e Camila.

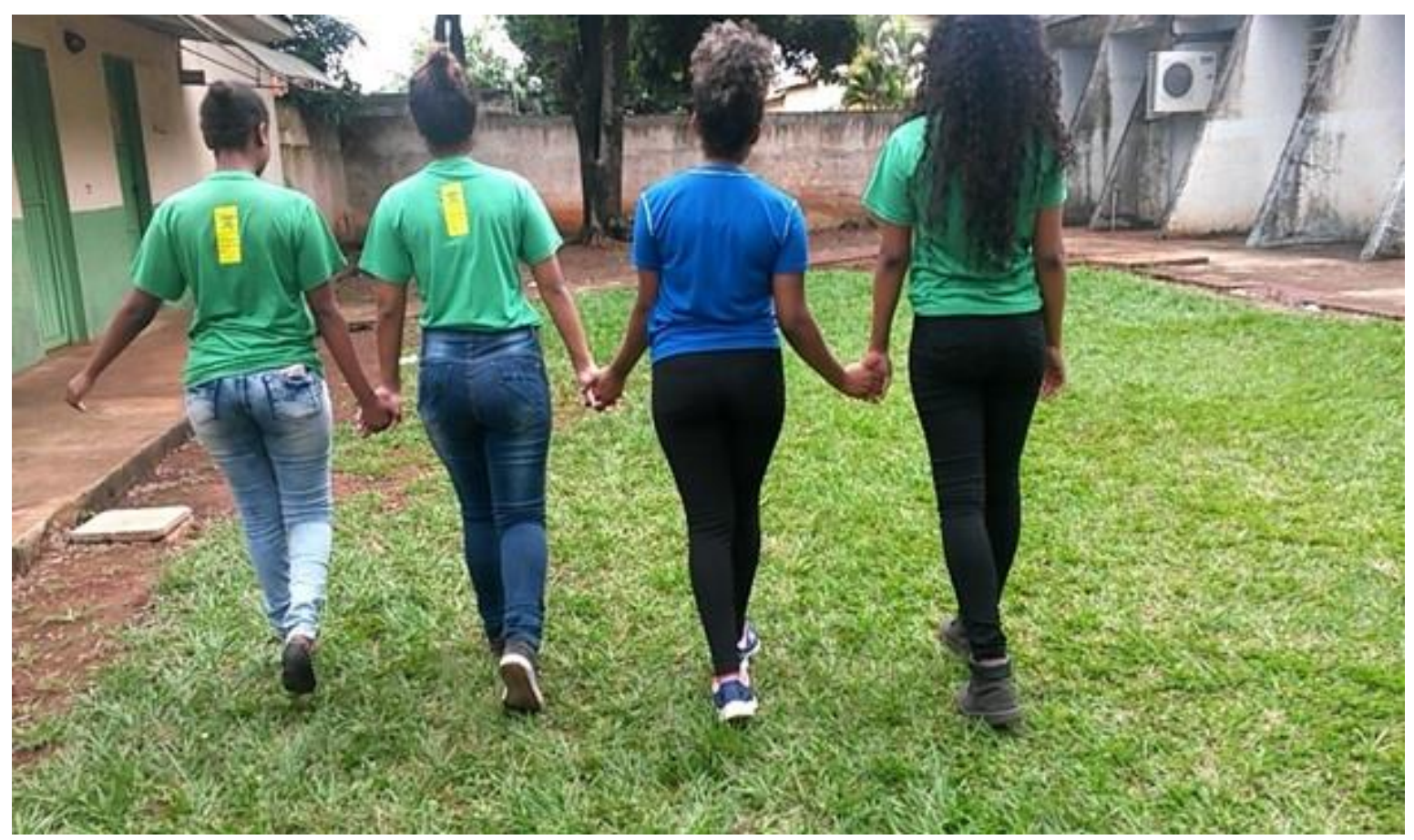

Figura 11- Racismo. Autoria: Ruana Dias, Luana Aguiar e Thiago Saraiva. 
O tema que motivou a foto da Figura 10 foi "Os afrodescendentes em Dourados: como são?". A pergunta presente no tema estimulou o grupo a fotografar um elemento da constituição física, característico dos afrodescendentes: os cabelos. Os cabelos encaracolados focados à luz do sol no céu azul produziram uma bela imagem. Seria a foto um questionamento ao estereótipo sobre os afrodescendentes (possuem "cabelos ruins" por nãos serem lisos) e ao próprio ideário construído em torno da ideia de belo e da beleza a partir dos padrões ocidentais brancos? Quais os sentidos geográficos presentes nesses questionamentos?

"O preconceito etnicorracial e suas expressões em Dourados" foi o tema motivador da foto da Figura 11. O próprio grupo responsável pela produção da foto identificou-se enquanto expressão do preconceito etnicorracial e se autorretratou. Uma espécie de selfie, sem rostos, de costas, mas com as mãos dadas. Quiseram alertar para o fato de que na escola também há expressões de preconceito etnicorracial? A foto ter sido realizada no pátio da escola e o fato de as meninas estarem vestidas com o uniforme da rede estadual de Mato Grosso do Sul foi uma forma de dizerem isso?

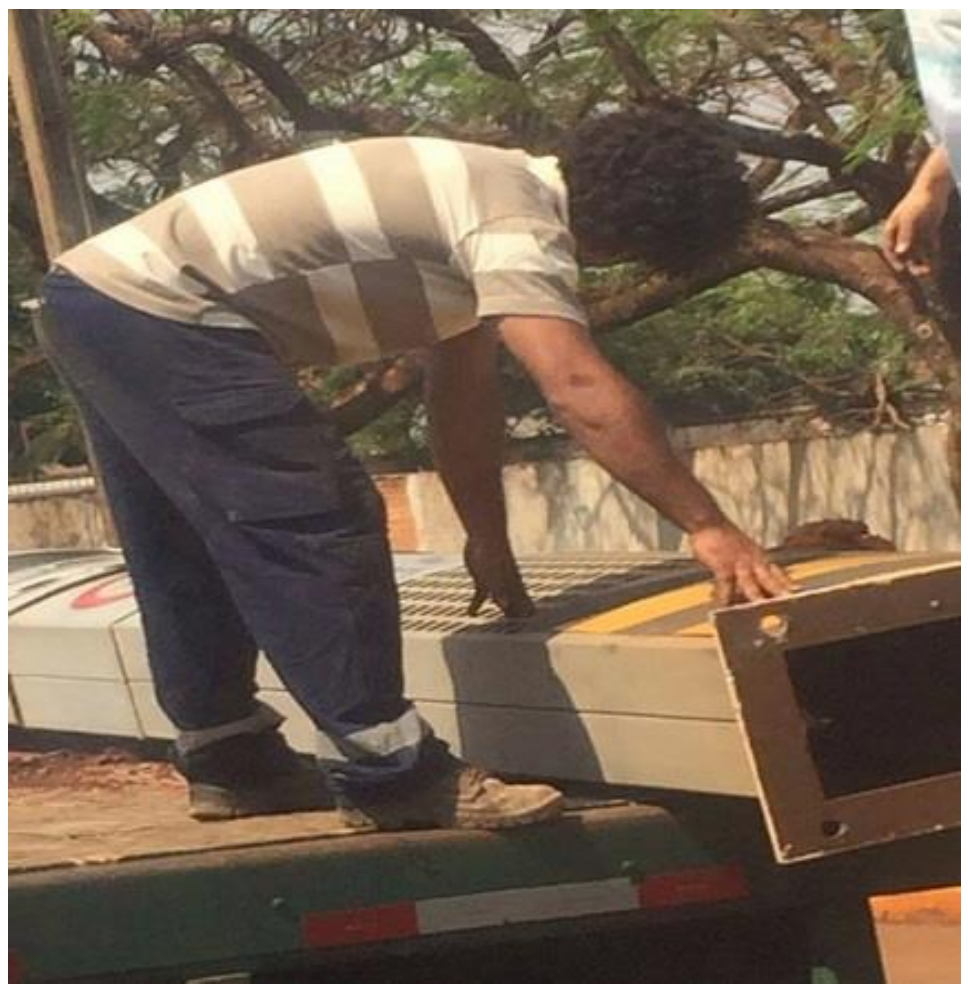

Figura 12 - Focado no trabalho.

Autoria: Amanda Rodrigues Barbosa, Giovana Marques, Laiane Augusto e Tainá Silva Santana 
"Focado no trabalho" foi o título dado pelo grupo de alunos à foto da Figura 12 que versou sobre o tema "Os afrodescendentes em Dourados: onde estão? O que fazem?". A relação entre a cena fotografada e o título dado à foto demonstra a intenção do grupo em enfatizar a forte presença dos afrodescendentes na realização de trabalhos pesados, que em grande parte, exigem pouca qualificação profissional e formação escolar. O título da foto também seria uma forma de dizer que para os afrodescendentes pouco resta além do trabalho? Seria uma forma de questionar as perspectivas colocadas para a maioria dos afrodescendentes em nossa sociedade? Quais fatos e processos histórico-geográficos explicam essa situação?

Muitas outras questões e reflexões podem ser feitas a partir das fotos. As vivências e experiências espaciais cotidianas vivenciadas pelos alunos e captadas nas imagens por eles produzidas, permitem percebermos os múltiplos sentidos dos lugares, provocando raciocínios e imaginações acerca de cada um deles e das relações que existem entre eles (OLIVEIRA JUNIOR, 2009, p. 10).

\section{Considerações Finais}

O principal objetivo das experiências aqui apresentadas foi o de permitir o estabelecimento de sentidos geográficos menores a partir da interpretação dos registros imagéticos dos alunos da educação básica em relação a temas e situações por eles vivenciados ou observados, além de exercitar habilidades de ensino e aprendizagem geográficas por meio de análises sobre a linguagem fotográfica.

A realização das experiências envolveu um conjunto de atividades e reflexões de ordem teórico-metodológica voltadas a problematizar e ampliar o entendimento sobre as linguagens imagéticas, principalmente a fotográfica no ensino de Geografia, na direção proposta por Oliveira Junior e Girardi (2011), segundo a qual é necessário tomar as linguagens como criadoras, ou seja, potencializadoras de pensamentos sobre o espaço.

Pode-se dizer que o trabalho despertou um olhar mais apurado dos alunos da educação básica sobre suas vivências e experiências espaciais cotidianas a partir das imagens registradas por eles próprios. Acreditamos que as fotografias produzidas pelos 
alunos provocaram o movimento do pensamento, na medida em que impulsionaram aqueles que as observaram a identificarem elementos, estabelecerem relações, comparações e produzirem indagações sobre o observado.

Mais questionamentos do que verdades e certezas. Mais elementos provocativos do pensamento do que ilustração ou prova de realidade. Tantas leituras tornaram-se possíveis porque as fotografias provocam em nós sensações diferentes. Neste sentido, as experiências aqui apresentadas tiveram a intenção de destacar essas potencialidades da linguagem fotográfica para a Geografia escolar.

Também é importante ressaltarmos que o PIBID se constituiu como um espaço/programa essencial para o desenvolvimento de reflexões e experiências desta natureza, na medida em que suas ações abrangem um processo de formação mais amplo que não se restringe à execução de práticas pedagógicas. Assim, a experiência, mais do que exercitar as potencialidades da fotografia junto aos alunos da educação básica, permitiu que os bolsistas de iniciação à docência, futuros professores de Geografia, fossem instigados a analisar e refletir sobre essa linguagem para além de um recurso didático que ilustra ou representa o conteúdo.

Num momento em que vivenciamos uma série de indefinições e ameaças quanto ao futuro e manutenção do PIBID, defendemos que esse programa traz contribuições muito significativas para a formação de professores, assim como para a educação básica. Acreditamos que as experiências e reflexões aqui realizadas trazem elementos que demonstram algumas dessas contribuições.

\section{Referências}

KOSSOY, Boris. Realidades e ficções na trama fotográfica. Cotia/SP: Ateliê Editorial, 2002.

OLIVEIRA JUNIOR, Wenceslao M. de. Fotos em sites: geografias da cultura contemporânea. Geografares, n. 7, 2009, p. 09-21.

OLIVEIRA JUNIOR, Wenceslao M. de. As geografias menores nas obras em vídeo de artistas contemporâneos. In: COLÓQUIO IBÉRICO DE GEOGRAFIA, XIV , Guimarães, 2014. 
Actas... Guimarães, 2014. Disponível em: https://geoimagens.files.wordpress.com/2014/12/wenceslao.pdf. Acesso em: 01 de outubro de 2015.

OLIVEIRA JUNIOR, Wenceslao M.; GIRARDI, Gisele. Diferentes linguagens no ensino de Geografia. In: ENCONTRO NACIONAL DE PRÁTICAS DE ENSINO DE GEOGRAFIA, XI, 2011. Goiânia. Anais... Goiânia, 2011, p. 1-9.

OLIVEIRA JUNIOR, Wenceslao M. de; SOARES, Elaine dos S. Fotografias didáticas e Geografia escolar entre evidências e fabulações. Revista Percursos. Florianópolis, v. 13, n. 02, p. 114 - 133, jul./dez. 2012.

SANTOS, Douglas. Conteúdo de objetivo pedagógico no ensino da Geografia. Caderno Prudentino de Geografia, Pres. Prudente: AGB, n. 17, p. 20-60, jul./dez. 2012.

SANTOS, Douglas. O que é Geografia? São Paulo, 2007, inédito.

SAYÃO, Lucas G. dos S.; NUNES, Flaviana G. A Geografia no Exame Nacional do Ensino Médio (ENEM): uma análise a partir das provas do período 2005-2008. Revista Ensino de Geografia. Uberlândia, v. 2, n. 3, p. 36 - 59, jul./dez. 2011 